\title{
Evaluation of clinico-epidemiological and histopathological features of pityriasis rosea
}

\author{
Gaye Devrim Özyürek¹, Sevil Alan², Erol Çenesizoğlu
}

\author{
${ }^{1}$ Department of Dermatology and Venereology, Private Modern World Hospital, Kayseri, Turkey \\ Head of Department: Gaye Devrim Özyürek \\ ${ }^{2}$ Department of Dermatology and Venereology, Faculty of Medicine, Akdeniz University, Antalya, Turkey \\ Head of Department: Erkan Alpsoy \\ ${ }^{3}$ Department of Dermatology and Venereology, Adana Numune Education and Research Hospital, Adana, Turkey \\ Head of Department: Erol Çenesizoğlu
}

\begin{abstract}
Introduction: Pityriasis rosea is a sudden-onset and self limiting disease with specific skin rash. The exact etiology is still not clear.

Aim: To determine epidemiological, etiological, clinical and histopathological features in pityriasis rosea (PR).

Material and methods: Fifty two patients (older than 18 years) with PR were included in this study. Patients were examined for epidemiological and etiological features. Biopsy specimens obtained from secondary eruptions were histopathologically evaluated with hematoxylin-eosine and immunohistochemically evaluated with CD3 and CD20 monoclonal antibodies.

Results: Age range of patients was 18-53, mean age was $29.3 \pm 9.5$ and women-to-men ratio was 1.08/1. Thirty-nine (75\%) patients had a history of wearing new clothes, 27 (51.9\%) patients had a history of recent respiratory tract infection, 15 (28.8\%) patients had a history of recent gastrointestinal infection. Eczematous changes were detected in biopsy materials by histopathological evaluation, and cellular infiltrate was positively stained with pan T-cell marker CD3 and negatively stained with B lymphocyte marker CD20 in all biopsy materials in immunohistochemical examination.

Conclusions: In our study, frequency of pre-disease infection and prodromal symptoms history were determined to be higher than the results of similar studies in the literature. These higher results suggest that PR may be delayed-type hypersensitivity to an infectious factor. However, positive staining of all biopsy materials with pan T lymphocyte marker CD3 supports the association with cellular immunity. We believe that more extensive studies are needed on this issue.
\end{abstract}

Key words: epidemiology, etiology, histopathology, pityriasis rosea.

\section{Introduction}

Pityriasis rosea (PR) is a sudden-onset, self-limiting disease with specific skin rash and rare systemic symptoms [1]. It usually occurs between 10 and 35 years of age [2, 3]. The PR is believed to be delayed-type hypersensitivity to an infectious factor [4]. Amongst infectious factors, viruses are first causes that are held responsible [5]. In addition, bad social and economic conditions and simultaneous case reports in family support the infectious etiology of disease [3]. Other reasons include fungal, bacterial and spirochete infections, autoimmunity, increase in T-helper/T-suppressor ratio, drugs and neoplastic diseases [6-8].

The initial lesion, which is also referred to as a herald patch (HP) is located on the trunk, and is a 2-10 cm oval or round patch which is erythematous, slightly elevated from the skin, and has a collar squama on it [9]. Secondary eruptions are oval, pink macular eruptions that have grayish squama [10]. Mucosa may be involved with particular involvement of the oral cavity [11, 12].

Address for correspondence: Sevil Alan MD, Akdeniz University, Akdeniz Universitesi Tıp Fak, Hastanesi Deri ve Zührevi Hast, ABD, 07070 Antalya, Turkey, phone: +905052184284, e-mail: alan_sevil@yahoo.com Received: 12.10 .2013 , accepted: 6.01.2014. 
Differential diagnosis includes drug eruption, seborrheic dermatitis, secondary syphilis, guttate psoriasis, pityriasis lichenoides, dermatophyte infection, erythema dyschromicum perstans. Treatment is usually administered for itching and cosmetic concerns [13].

\section{Aim}

The aim of the study was to determine epidemiological, etiological, clinical and histopathological features in PR.

\section{Material and methods}

Patients aged 18-53 who presented to the dermatology clinic between February 2008 and December 2008 and clinically diagnosed as PR. Patients under 18 years, pregnant women and patients with systemic diseases were excluded. The local ethics committee approval was obtained and all patients gave informed consent form before trial.

History of atopy, history of recent infection, presence of similar or same disease in relatives, drug use and history of the same disease was examined in the first evaluation.

All patients were tested for blood count, erythrocyte sedimentation rate (ESR), anti-streptolysin O (ASO), C-reactive protein (CRP), rheumatoid factor (RF), total protein, albumin, IgG, IgM, IgA, IgE, C3, ANA,VDRL, anti HIV and throat cultures. Six millimetres $\mathrm{mm}$ punch biopsy was obtained from secondary eruptions for histopathological evaluation. Sections of 4 microns were stained with hematoxylin eosin. Sections were stained with CD3 and CD20 monoclonal antibodies for immunohistochemical examination. Positivity of CD3 (pan T-cell marker) and CD20 (B-cell marker) was evaluated to detect the nature of mononuclear cell infiltrate.

\section{Statistical analysis}

SPSS 16.00 package program was used for statistical analysis of data. Categorical measurements were summarized as figures and percentage, whereas continuous measurements were summarized as mean and standard deviation.

\section{Results}

A total of 52 patients with PR (of which 27 (51.99\%) were women and 25 (48.1\%) were men) were included in the study. Women-to-men ratio was 1.08/1. The demographical data of the patients are given in Table 1.

The average disease period of the patients, localization of HP, the period between HP and secondary eruptions, etc. are presented in Table 2.

Although the mean values of all laboratory tests were within normal limits, increases in levels of total protein,
Table 1. Demographic characteristics of patients with PR

\begin{tabular}{|c|c|}
\hline Characteristics & $\begin{array}{c}\text { Number of patients } \\
n(\%)\end{array}$ \\
\hline Age, range (mean \pm SD) [years] & $18-53(29.3 \pm 9.5)$ \\
\hline \multicolumn{2}{|l|}{ Age groups: } \\
\hline $18-25$ & $23(44.2)$ \\
\hline $26-30$ & $10(19.2)$ \\
\hline $31-40$ & $13(25)$ \\
\hline$>40$ & $6(11.6)$ \\
\hline \multicolumn{2}{|l|}{ Gender: } \\
\hline Female & $27(51.9)$ \\
\hline Male & $25(48.1)$ \\
\hline \multicolumn{2}{|l|}{ Distribution of patients by months: } \\
\hline February & $7(13.5)$ \\
\hline March & $8(15.4)$ \\
\hline April & $10(19.2)$ \\
\hline May & $4(7.7)$ \\
\hline June & $5(9.6)$ \\
\hline July & $2(3.8)$ \\
\hline August & $3(5.8)$ \\
\hline September & $5(9.6)$ \\
\hline October & $4(7.7)$ \\
\hline November & $4(7.7)$ \\
\hline \multicolumn{2}{|l|}{ Occupational distribution of patients: } \\
\hline Worker & $20(38.5)$ \\
\hline Housewife & $18(34.6)$ \\
\hline Student & $6(11.5)$ \\
\hline Civil servant & $3(5.8)$ \\
\hline Retired & $3(5.8)$ \\
\hline Unemployed & $2(3.8)$ \\
\hline \multicolumn{2}{|l|}{ Infectious conditions prior to PR: } \\
\hline History of wearing new clothes & $39(75)$ \\
\hline History of respiratory tract infection & $27(51)$ \\
\hline History of gastrointestinal infection & $15(28.8)$ \\
\hline History of injection & $13(25)$ \\
\hline Bug bite & $6(11.5)$ \\
\hline Contact with an animal & $5(9.6)$ \\
\hline Vaccination & $3(5.8)$ \\
\hline Cicatrisation & $3(5.8)$ \\
\hline History of trauma & $2(3.8)$ \\
\hline History of drug use prior to PR & $21(40.3)$ \\
\hline History of atopy & $14(27)$ \\
\hline History of previous PR & $1(1.9)$ \\
\hline
\end{tabular}


Table 2. Clinical characteristics of patients with PR

\begin{tabular}{|c|c|}
\hline Characteristics & $\begin{array}{c}\text { Number of patients } \\
n(\%)\end{array}$ \\
\hline Disease duration, mean \pm SD [day] & $26.5 \pm 30.7$ \\
\hline Presence of herald patch & $40(76.9)$ \\
\hline \multicolumn{2}{|l|}{ Location of herald patch: } \\
\hline Trunk & $22(55)$ \\
\hline Arm & $5(12.5)$ \\
\hline Forearm & $4(10)$ \\
\hline Thigh & $3(7.5)$ \\
\hline Leg & $3(7.5)$ \\
\hline Neck & $2(5)$ \\
\hline Gluteal area & $1(2.5)$ \\
\hline \multicolumn{2}{|l|}{$\begin{array}{l}\text { Time between HP and secondary } \\
\text { eruption [days]: }\end{array}$} \\
\hline $1-5$ & $19(47.5)$ \\
\hline $6-10$ & $16(40)$ \\
\hline More than 11 & $5(12.5)$ \\
\hline \multicolumn{2}{|l|}{ Type of secondary eruption: } \\
\hline Macules with collar squama & $45(86.5)$ \\
\hline Purpuric lesions & $3(5.8)$ \\
\hline Urticarial plaques & $3(5.8)$ \\
\hline Lichenoid lesions & $1(1.9)$ \\
\hline \multicolumn{2}{|l|}{$\begin{array}{l}\text { Distribution pattern of secondary } \\
\text { eruptions: }\end{array}$} \\
\hline Christmas tree patern & $47(90.4)$ \\
\hline Parallel to ribs patern & $4(7.7)$ \\
\hline Reverse Christmas tree & $1(1.9)$ \\
\hline \multicolumn{2}{|l|}{ Presence of prodromal symptoms: } \\
\hline Headache & $22(42.3)$ \\
\hline Fever & $15(29)$ \\
\hline Arthralgia & $12(23)$ \\
\hline \multicolumn{2}{|l|}{ Clinical features: } \\
\hline Itching & $40(76.9)$ \\
\hline Fatique & $27(51.9)$ \\
\hline Lymphadenopathy & $2(3.8)$ \\
\hline
\end{tabular}

erythrocyte sedimentation rate, albumin, IgE, IgG, ASO, CRP and IgM were observed (Table 3). C3 and IgA values were normal in all patients. Anti-HIV, ANA and VDRL tests were negative for all patients. The RF positivity was detected in 5 (9.6\%) patients. Normal flora and pathogen bacteria grew in throat cultures of 41 (78.7\%) and $11(21.2 \%)$ patients, respectively, and in $9.6 \%$ of them, growth bacteria was $\beta$-hemolytic streptococcus alone.
Table 3. Laboratory findings of patients with PR

\begin{tabular}{lc}
\hline \multicolumn{1}{c}{ Laboratory findings } & $\begin{array}{c}\text { Numberof patients } \\
n(\%)\end{array}$ \\
\hline Elevation of ESR & $18(34.6)$ \\
\hline Elevation of total protein & $17(33)$ \\
\hline Elevation of IgE & $14(27)$ \\
\hline Elevation of albumin & $12(23)$ \\
\hline Elevation of IgG & $4(7.6)$ \\
\hline Elevation of ASO & $3(5.8)$ \\
\hline Elevation of CRP & $3(5.8)$ \\
\hline Elevation of IgM & $2(3.8)$ \\
\hline Positivity of RF & $5(9.6)$ \\
\hline Anemia & $10(19.2)$ \\
\hline Eosinophilia & $8(15.3)$ \\
\hline Growth in throat culture & $11(21.2)$ \\
\hline
\end{tabular}

Table 4. Histopathological findings of patients with PR

\begin{tabular}{ll}
\hline \multicolumn{1}{c}{ Histopathological findings } & $\begin{array}{c}\text { Number of patients } \\
n(\%)\end{array}$ \\
\hline Epidermal changes: & $36(69.2)$ \\
\hline Irregular acanthosis & $32(61.5)$ \\
\hline Focal parakeratosis & $30(57.3)$ \\
\hline Dyskeratosis & $29(55.8)$ \\
\hline Spongiosis & $27(51.9)$ \\
\hline Thickening in suprapapillary layer & $17(32.7)$ \\
\hline Lymphocytic exocytosis & $12(23.1)$ \\
\hline Hyperkeratosis & $3(5.8)$ \\
\hline Loss or thinning of granular layer & $1(1.9)$ \\
\hline Intraepidermal vesicle & \\
\hline Dermal changes: & $51(98.1)$ \\
\hline Perivascular lymphocytic infiltration & $33(63.5)$ \\
\hline Periglandular lymphocytic infiltration & $24(46.2)$ \\
\hline Hyalinisation in papillary collagen & $21(40.4)$ \\
\hline Erythrocyte extravasation & $21(40.4)$ \\
\hline Perifollicular lymphocytic infiltration & \\
\hline
\end{tabular}

In more than half of the biopsy materials, perivascular lymphocytic infiltration, irregular acanthosis and spongiosis were observed (Table 4).

Evaluation of nature of lymphocytic infiltration by immunohistochemical method revealed that the lymphocytes were positively stained with pan T lymphocyte marker CD3 (Figure 1) and negatively stained with B-lymphocyte marker CD20 in all patients. 


\section{Discussion}

The PR is a sudden-onset, self-limiting disease with specific skin rash and usually affects the children and adolescents [1]. Generally, PR equally affects both of the genders [2]. In our study, women-to-men ratio was also almost equal with the ratio of 1.08/1. Different results have been reported on seasonal distribution of PR [14, 15]. The PR may become epidemic in crowded living spaces such as school, family and workplaces [5]. The fact that most of our patients were workers, housewives and people living with a family of $\geq 4$ persons appears to support the epidemic nature of disease in crowded living spaces. The PR is sometimes observed in the areas of bug bite, minor skin infection, previous scars, injection sites or BCG vaccination. Furthermore, new, unwashed clothes or clothes held dirty for a long time suggested to be associated with the disease $[12,15]$. In our study, most of patients had a history of wearing new clothes, history of recent respiratory tract infection and gastrointestinal infection.

Prodromal symptoms are rare [1]. However, occasionally prodromal findings such as fever, headache, arthralgia, cough, vomiting and lymphadenopathy may be observed [9]. Frequency of prodromal symptoms was determined to be $59.6 \%$ in our study. This rate is higher than the rates found in the literature $[9,10,12,13]$. This higher rate supports the role of viral infections in PR etiology.

Frequency of HP ranges between $40 \%$ and $76 \%$ amongst various studies [10]. Frequency of HP in our study (76.9\%) was similar to that of other studies. Secondary eruptions occurred within 10 days after HP in $62.5 \%$ of the patients in the study of Sharma et al. and $87.5 \%$ of the patients in our study [13].

Usually, there is no disease-specific laboratory finding. However, sometimes leucocytosis, neutrophilia, eosinophilia, basophilia and lymphocytosis may be observed in whole blood count [10]. In a study of Sharma et al., leukocyte count and hemoglobin levels were normal in all patients, and eosinophilia was detected in 16\% of the patients [13]. In study of Cheong, leukocyte count was normal in $97.9 \%$ of the patients [15]. Increases in the erythrocyte sedimentation rate, total protein and albumin, IgM elevation and decreases in C3 levels were observed in some studies [6, 9]. Specific T lymphocytes against Group A streptococcus antigen were found in PR in a study conducted. ASO levels were normal [10].

Histopathologic features of PR are not specific. Eczematous changes are observed during the early phase, whereas parapsoriasis en plaque-like changes are observed in the late phase [14]. The study conducted by Okamoto et al. in 29 patients with PR, perivascular lymphocytic infiltration was detected in all biopsy materials and erythrocyte extravasation was detected in $66 \%$ of biopsy materials [16]. Panizzon et al. evaluated 62 biopsy materials with light microscope in their study and the main characteristic feature was determined as eczem-
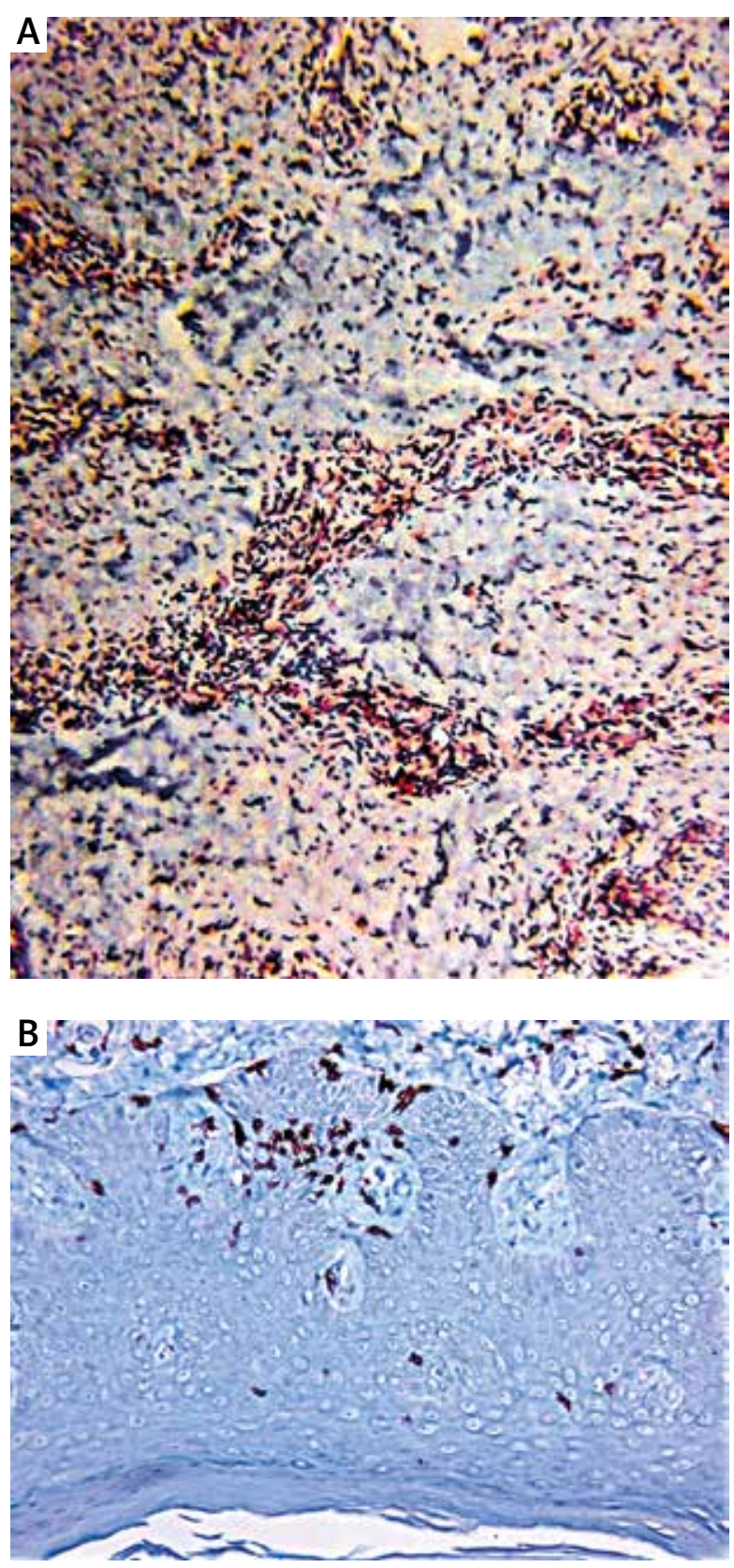

Figure 1. Lymphocytic infiltrate with $\mathrm{CD} 3$ positive staining. Original magnification $200 \times(A)$ and $400 \times(B)$

atous manifestation [17]. Similar rates were reported in a similar study conducted by Aiba et al. in 13 patients with PR [14]. In our study, observation of perivascular lymphocytic infiltration focal parakeratosis, irregular acanthosis and spongiosis in more than half of our biopsy materials appear to support the eczema-like histopathologic features of PR (Figure 2). The presence of exocytosis of lymphocytes within the epidermis, seen on histopathological examination in most of the specimens, suggests a possible interaction between epidermal components 

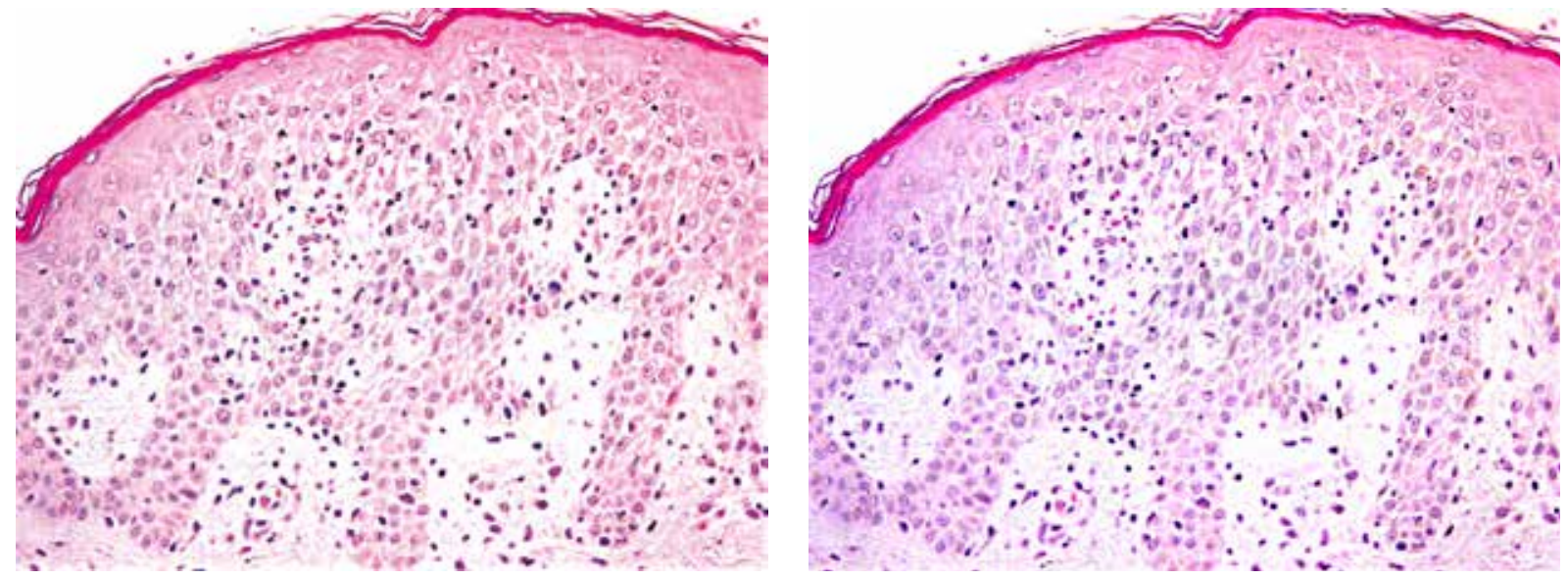

Figure 2. Epidermal exocytosis with superficial perivascular infiltrate of lymphocytes (haematoxylin and eosin, original magnification 200x)

and dermal mononuclear cells in the pathomechanism of PR. It also supports a possible cellular immunity underlying PR. Moreover, dyskeratosis was observed in 30 (57.3\%) patients in our study. This ratio was reported as $55 \%$ in the study of Okamoto et al. and as $1 \%$ in the study of Aiba et al. [14, 16]. In the study of Neoh et al. carried out on 12 biopsy materials, dyskeratosis was not mentioned [18]. The presence of dyskeratotic cells in PR has not caught the attention of many related quarters perhaps on account of the fact that skin biopsy is rarely conducted since PR can be easily diagnosed clinically. Although Stern et al. reported that several dyskeratotic cells were observed, they considered it as an incidental finding [19]. The fact that we encountered dyskeratotic cells in $57.3 \%$ of our cases well indicates that the occurrence of dyskeratotic cell might not be accidental but rather on account of an underlying fundamental process. Since dyskeratotic cells are considered to emerge due to the damage of basal epidermal cells, their presence suggests that primary damage of basal cells may also occur in PR. Furthermore, the erythrocyte extravasation that was observed in nearly half of our biopsy materials supports the concept of dermal vascular damage. Cellular immunity is obviously of importance in PR etiology [14]. In a study conducted by Aiba et al., all perivascular mononuclear cells and most of the epidermotropic cells in all of 10 biopsy materials were positively stained with anti-pan T cell antibody CD3 [14]. In a study conducted by Hussein et al., the immunohistochemistry results attested significantly high counts of immune cells in lesional skin allergic contact dermatitis, atopic dermatitis and pityriasis rosea ( $A C D, A D$ and $P R$ ) compared to the normal ones. The immune cells are composed predominantly of CD3 (+) T lymphocytes and CD68 (+) cells (histiocytes) in the lesional skin. Although the counts of CD2O (+) cells were determined to be high in PR compared to ACD and AD, these differences did not reach a statistically significant level [20]. In the study conducted by Neoh et al. on the
12 biopsy materials, positive immunostaining was defined as $>5 \%$ of stained cells within the infiltrate. In all 12 biopsies, the dermal infiltrate of lymphocytes stained positively for monoclonal antibodies specific for $T$ cells (CD2-CD5 and CD8) and in 7 of 12 biopsies, positive staining with CD7 (pan-T-cell marker) was seen. The ratio of the CD4+ (helper) vs. CD8+ (cytotoxic) T cells in the dermal infiltrate was increased in 10 of 12 specimens. CD20 staining for B cells was found to be negative in the dermal and epidermal infiltrates of all the patients [18]. When the nature of lymphocytic infiltration was examined by immunohistochemical method in our study, lymphocytes were observed to be positively stained with pan T lymphocyte marker CD3 and negatively stained with B-lymphocyte marker CD20 in all the patients. This finding well supports the assumption that disease is rather associated with cellular immunity.

Limitations of our study include its configuration as a single-center study, small number of patients and absence of the control group.

\section{Conclusions}

The fact that most of the patients in our study had a history of recent respiratory tract infection and history of gastrointestinal infection makes us to think that PR may be delayed-type hypersensitivity to an infectious factor. In addition, positive staining of all biopsy materials with pan T lymphocyte marker CD3 supports the relationship with cellular immunity. We are of the opinion that our study is bound to contribute a lot to epidemiologic and histopathologic data on PR. However, further prospective, long-term and multi-center studies are needed on this disease.

\section{Conflict of interest}

There is no conflict of interest. 


\section{References}

1. Sterling JC, Burns T, Breathnach S, et al. Virus infections. Rook's Textbook of Dermatology 2004; 25: 79-83.

2. Tay YK, Goh CL. One-year review of pityriasis rosea at the National Skin centre, Singapore. Ann Acad Med Singapore 1999; 28: 829-31.

3. Lemster N, Neumark M, Arieh I. Pityriasis rosea in a woman and her husband - case report and review of the literature. Case Rep Dermatol 2010; 6: 135-9.

4. Gulekon A. Psoriasis and similar dermatoses. In: Dermatology. Tuzun Y, Gurer MA, Serdaroglu S, et al. (eds.). Istanbul 2008; 756-8.

5. Drago F, Broccolo F, Rebora A. Pityriasis rosea: an update with a critical appraisal of its possible herpesviral etiology. J Am Acad Dermatol 2009; 61: 303-18.

6. Bangash HK, Finch T, Petronic-Rosic V, et al. Pityriasis rosea-like drug eruption due to nortriptyline in a patient with vulvodynia. J Low Genit Tract Dis 2013; 17: 226-9.

7. Chuh AA. A prospective case-control study of autoimmune markers in patients with pityriasis rosea. Clin Exp Dermatol 2003; 28: 449-50.

8. Maciej O, Czesław Z. Epidemiology, etiology, pathogenesis and risk factors of mother-to-child-transmission of HIV. Postep Derm Alergol 2012; 29: 128-31.

9. Cheong WK, Wong KS. An epidemiological study of pityriasis rosea in Middle Road Hospital Singapore. Med J 1989; 30: 60-2.

10. Björnberg A, Tegner E, Freedberg IM, et al. Pityriasis rosea Fitzpatrick's dermatology in general medicine. USA 2003; 445-50.

11. Kay MH, Rapini RP, Fritz KA. Oral lesions in pityriasis rosea. Arch Dermatol 1985; 121: 1449-51.

12. Slebioda Z, Szponar E, Kowalska A. Recurrent aphthous stomatitis: genetic aspects of etiology. Postep Derm Alergol 2013; 30: 96-102.

13. Sharma L, Srivastava K. Clinicoepidemiological study of pityriasis rosea. Indian I Dermatol Venereol Leprol 2008; 74: 647-9.

14. Aiba S, Tagami H. Immunohistologic studies in pityriasis rosea. Evidence for cellular immune reaction in the lesional epidermis. Arch Dermatol 1985; 121: 761-5.

15. Alsaad KO, Ghazarian D. My approach to superficial inflammatory dermatoses. J Clin Pathol 2005; 58: 1233-41.

16. Okamoto H, Imamura S, Aoshima T, et al. Dyskeratotic degeneration of epidermal cells in pityriasis rosea: light and electron microscopic studies. Br J Dermatol 1982; 107: 189-94.

17. Panizzon R, Bloch PH. Histopathology of pityriasis rosea Gibert: qualitative and quantitative light microscopic study of 62 biopsies of 40 patients. Dermatologica 1982; 165: 551-8.

18. Neoh CY, Tan AWH, Mohamed K, et al. Characterization of the inflammatory cell infiltrate in herald patches and fully developed eruptions of pityriasis rosea. Clin Exp Dermatol 2010; 35: 300-4.

19. Stern JK, Wolf JE, Rosen T. Focal acantholytic dyskeratosis in pityriasis rosea. Arch Dermatol 1979; 115: 497.

20. Hussein MR, Abdel-Magid WM, Saleh R, Nada E. Phenotypical characteristics of the immune cells in allergic contact dermatitis, atopic dermatitis and pityriasis rosea. Pathol Oncol Res 2009; 15: 73-9. 